\title{
The sorption of toxic elements onto natural zeolite, synthetic goethite and modified powdered block carbon
}

\author{
Valquiria Campos
}

Received: 2 May 2008/ Accepted: 13 January 2009/Published online: 20 February 2009

(C) The Author(s) 2009. This article is published with open access at Springerlink.com

\begin{abstract}
Inorganic elements analyses of Carapicuíba lake reveal that $\mathrm{As}, \mathrm{Cr}, \mathrm{Pb}$ and $\mathrm{Mn}$ are above the recommended drinking water standards. The mean total concentrations of toxic elements in surface water decrease in the order $\mathrm{Mn}>\mathrm{Cr}>\mathrm{Pb}>$ As. At elevated concentrations, toxic elements like $\mathrm{Cr}$ can accumulate in soils and enter the food chain, leading to serious health hazards and threatening the long-term sustainability of the local ecosystem. Absorbing materials has often been used to improve water quality. In this investigation three types of material were studied: the natural zeolite (mordenite); synthetic goethite and the powdered block carbon modified. The adsorption of $\mathrm{Pb}^{2+}$ and $\mathrm{Mn}^{2+}$ onto natural zeolite as a function of their concentrations was studied at $24^{\circ} \mathrm{C}$ by varying the metal concentration from 100 to $400 \mathrm{mg} \mathrm{L}^{-1}$ while keeping all other parameters constant. The low-cost zeolites removed $\mathrm{Pb}$ from water without any pretreatment at $\mathrm{pH}$ values $<6$. The maximum adsorption attained was as follows: $\mathrm{Pb}^{2+} 78.7 \%$ and $\mathrm{Mn}^{2+} 19.6 \%$. The modified powdered block carbon effectively removed $\mathrm{As}(\mathrm{V})$ and $\mathrm{Cr}(\mathrm{VI})$ while goethite removed more chromate than arsenate in the $\mathrm{pH}$ range 5-6. Results of this study will be used to evaluate the application these materials for the treatment of the Carapicuíba lake's water.
\end{abstract}

Keywords Pollutants · Adsorbents - Removal · Water quality

V. Campos $(\bowtie)$

Department of Chemical Engineering, Polytechnic School,

University of São Paulo, Rua Marie Nader Calfat, 351-71

Evoluti, Morumbi, São Paulo, SP 05713-520, Brazil

e-mail:vcampos@usp.br

\section{Introduction}

The widening and deepening of the gutter of the river Tietê in the metropolitan area of São Paulo, Brazil, as a tool to prevent the periodic floods in this region, had important environmental consequences. A large amount of sediment, rocks and garbage has been removed from the river and has been deposited in Carapicuíba lake. The lake, covering an area of about $770.000 \mathrm{~m}^{2}$ is located in the metropolitan region of São Paulo. The present study chemically characterized water samples from the Carapicuíba lake by determining metal concentration and other elements of interest. The chosen chemical parameters for this characterization were arsenic, chromium, lead and manganese. Minor and trace elements sorption on materials including natural zeolite, synthetic goethite, and modified block carbon was the main argument of the present study.

Many type of adsorbents have been used for removal of arsenic by adsorption from aqueous effluents. They can be classified into three main groups. The first includes the adsorbents based on aluminum which can be used either as $\gamma \mathrm{Al}_{2} \mathrm{O}_{3}$ activated alumina or as $\mathrm{Al}(\mathrm{OH})_{3}$ (gibbsite). Another element used for arsenic adsorption is lanthanum which is used as lanthanum hydroxide, lanthanum carbonate or lanthanum oxide. Iron is, however, the most used element as arsenic adsorbents in a large variety of forms. The predominant iron compounds are goethite $(\alpha-\mathrm{FeO} \cdot \mathrm{OH})$, hematite $\left(\alpha-\mathrm{Fe}_{2} \mathrm{O}_{3}\right)$ or iron oxide coated sand. Also other type of adsorbents based on iron such as Fe(III) loaded coral limestone, ferric chloride, industrial solid waste [waste $\mathrm{Fe}(\mathrm{III}) / \mathrm{Cr}$ (III) hydroxide], granular ferric hydroxide, pyrite, ferrihydrite, fly ash have also been investigated (Tokunaga et al. 1997; Fendorf et al. 1997; Namasivayam and Senthilkumar 1998; Driehaus et al. 1998; Rau et al. 2000; Bhattacharyya et al. 2003; Campos 2002). 
Lead is one of the most toxic metals and all over the world guidelines set the maximum acceptable concentration of lead in drinking water at very low levels. The mobility of lead in organism and its toxicity for human health are well known. The toxicity of this element is further complicated by redox $\mathrm{Pb}^{4+} / \mathrm{Pb}^{2+}$ reaction (Tomašević-Čanović 2005). The European Community Directive 98/83 and the WHO guidelines set the value for tap waters at $10 \mu \mathrm{g} \mathrm{L}^{-1}$ from December 2013, lowering the previous of the $50 \mu \mathrm{g} \mathrm{L}^{-1}$, with a transient step at $25 \mu \mathrm{g} \mathrm{L}{ }^{-1}$ from 2003 to 2013. A literature overview has brought out five categories of media able to remove lead from water. The most efficient ones are natural or synthetic zeolites. Metallic oxides such a manganese dioxide proved to be also very efficient (Wilkie and Hering 1996). Finally, activated carbons, ion exchange resins, and biosorbents such as chitine or cellulose xanthate have also been used for lead removal (Roberts et al. 2004).

Manganese is a naturally-occurring element that can be found ubiquitously in the air, soil, and water. Manganese is naturally occurring in many surface and groundwater as dissolved or suspended material. However, human activities are also responsible for much of the manganese contamination in water in some areas. Although manganese is an essential nutrient at low doses, chronic exposure to high doses may be harmful. The health effects from overexposure of manganese are dependent on the route of exposure, the chemical form, the age at exposure, and the individual's nutritional status. Many of the reports of adverse effects from manganese exposures in humans are from inhalation exposures in occupational settings. Although there are substantial data supporting the neurological effects of inhaled manganese in both humans and animals, there are few data for the association between oral exposure to manganese and toxic effects. For example, several epidemiological studies associate adverse neurological effects with exposure to manganese from drinking water; however, due to a lack of qualitative and quantitative details of the exposure scenario, these studies cannot be used for quantitative assessment (USEPA 2004).

The chemical properties that make chromium such an important component of so many industrial and consumer products are also important factors controlling its environmental fate and toxicity. Hexavalent chromium exists in soils as a relatively soluble anion under most conditions $\left(\mathrm{CrO}_{4}^{2-}\right.$ or $\left.\mathrm{HCrO}_{4}^{-}\right)$; it is a class $\mathrm{A}$ human carcinogen by inhalation and may be acutely toxic or irritating to living cells. In contrast, $\mathrm{Cr}$ (III) is nontoxic, essential for human health, and found predominantly in insoluble forms in soils, or as sparingly soluble $\mathrm{Cr}_{2} \mathrm{O}_{3}$ and $\mathrm{Cr}(\mathrm{OH})_{3}$ (Dragun 1997). Various methods used for the removal of chromium ions from water include chemical precipitation, reverse osmosis, evaporation, ion exchange and adsorption. Several authors have reported studies on various low-cost adsorbents (Selvi et al. 2001; Selvaraj et al. 2003; Campos and Buchler 2005; Campos et al. 2007).

The use of surface water resources has increased over the last years at São Paulo Capital, Brazil, and this tendency will continue, due to demographic increase and relative advantages of the use of surface water instead of groundwater. The adsorption of $\mathrm{Pb}^{2+}$ and $\mathrm{Mn}^{2+}$ ions onto Brazilian natural zeolite in batch adsorber was studied. The present study also reports removal of $\mathrm{As}(\mathrm{V})$ and $\mathrm{Cr}(\mathrm{VI})$ by sorption onto laboratory-prepared pure goethite samples and powdered modified block carbon. In addition, the mechanism of the sorption of cations and anions in aqueous solution by a natural and modified materials. The results of this study are presented here.

\section{Materials and methods}

The zeolite used in this study is Brazilian natural mordenite from the western portion of São Paulo State. The Serra Geral flood basalts cover an area of approximately $1.2 \times 10^{6} \mathrm{~km}^{2}$, which corresponds to $75 \%$ of Parana Basin. The Serra Geral flood basalt province is one of the largest of the world with a total volume of lava flows exceeding $1.0 \times 10^{6} \mathrm{~km}^{3}$. The Serra Geral Formation comprises a variety of basic ( $90 \%$ of total volume), intermediate $(7 \%)$ and acid rocks (3\%). It is important to mention that interesting rocks for this study usually present a vesicular texture with some vesicles filled with zeolites. The chemical composition and specific surface area are presented in Table 1. The idealized chemical formula of the mordenite may be written as: $\mathrm{Na}_{3} \mathrm{KCa}_{2}\left(\mathrm{Al}_{8} \mathrm{Si}_{40} \mathrm{O}_{96}\right)$ $28 \mathrm{H}_{2} \mathrm{O}$. The mineralogical composition of natural zeolite used in experiments is dominated by mordenite (about 96\%). The individual mordenite fibre is visible in the scanning electron microscopy picture shown in Fig. 1.

Goethite and hematite have been used as model adsorbents because they have a well defined crystal structure, are widespread in nature and can be synthesized readily in the laboratory. Since the first report of Böhm in 1925 on synthesis of pure goethite, several attempts have been made to prepare material of uniform shape and size. Goethite can be synthesized in a few days by using high $\mathrm{OH}^{-}$concentrations and temperature of $70^{\circ} \mathrm{C}$. The properties of

Table 1 Selected properties of zeolite (mordenite)

\begin{tabular}{lllllll}
\hline Sample & $\mathrm{pH}$ & $\mathrm{CEC}^{\mathrm{a}}$ & \multicolumn{4}{l}{ Exchangeable cations [cmol(+) $\left.\mathrm{kg}^{-1}\right]$} \\
\cline { 3 - 7 } & & & $\mathrm{K}^{+}$ & $\mathrm{Na}^{+}$ & $\mathrm{Ca}^{2+}$ & $\mathrm{Mg}^{2+}$ \\
\hline Mordenite & 7.56 & 125 & 33.2 & 16.7 & 65.4 & 2.64 \\
\hline
\end{tabular}

${ }^{\mathrm{a}} \mathrm{NH}_{4} \mathrm{OAc}, \mathrm{pH} 7.0$ 

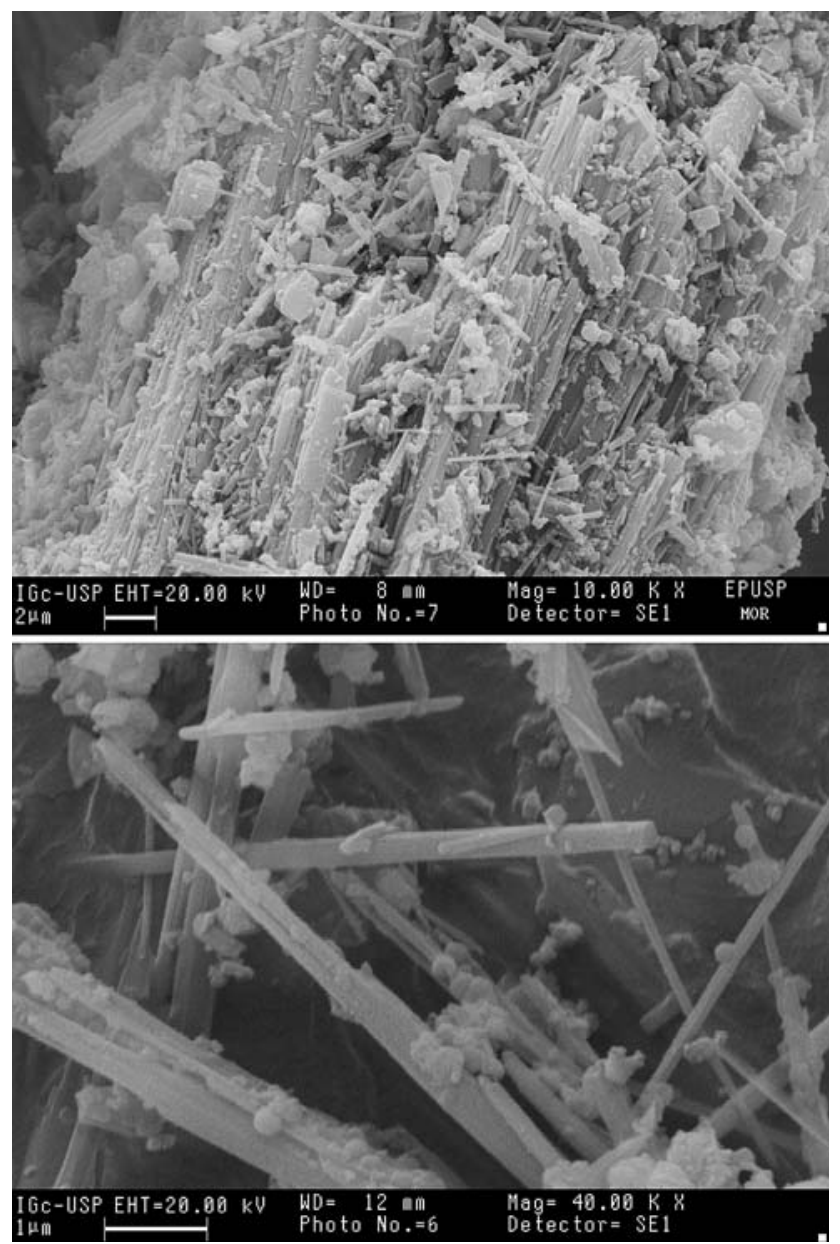

Fig. 1 SEM photograph of the natural zeolite with mordenite fibres $(10,000$ and $\times 40,000)$

goethite have been studied in considerable detail (Cornell and Schwertmann 2003). Pure goethite samples were prepared in the laboratory following the reported procedure using $1 \mathrm{M}$ ferric nitrate and $10 \mathrm{M}$ sodium hydroxide solutions under controlled conditions (Mohapatra et al. 2002). Ferric nitrate solution was vigorously stirred at room temperature with the simultaneous addition of $10 \mathrm{M}$ sodium hydroxide solution until the $\mathrm{pH}$ of the solution reached 12. The suspension thus obtained was kept in a polythene bottle at $343 \mathrm{~K}$ for $24 \mathrm{~h}$. The slurry was filtered and precipitate was washed with water until the filtrate was free of nitrate and sulfate. Goethite crystals are usually acicular and elongated along the crystallographic $c$ direction (Fig. 2).

Powder carbon steel ML-90 (DIN 1010) Bombril S. A. and activated carbon block were also used in experiments. The materials were analysed for elemental composition using a scanning electron microscope coupled to X-ray energy-dispersive spectroscopy (LEO 440i, Oxford). The SEM micrographs in Figs. 3 and 4 show the micromorphology of the powder carbon steel and PBC used in this
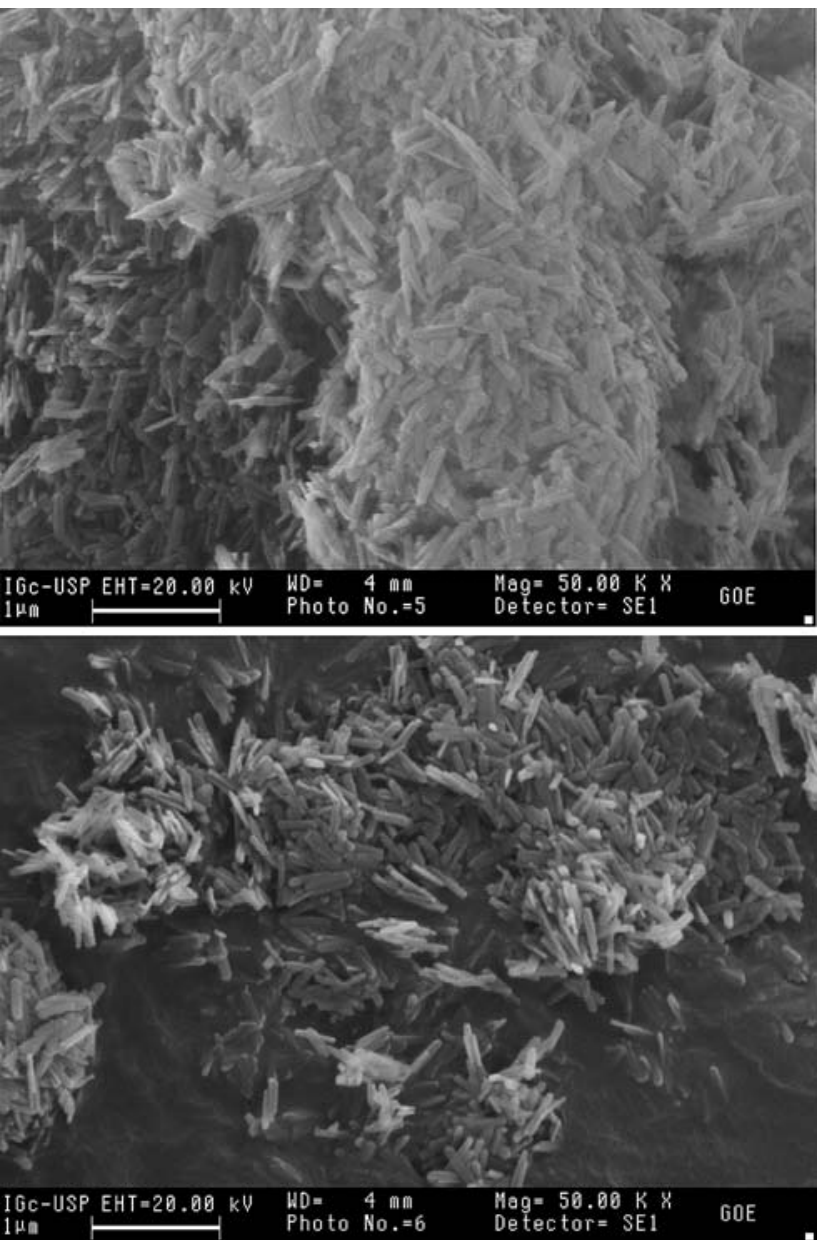

Fig. 2 Synthetic goethite where goethite crystals are usually acicular and elongated along the crystallographic $c$ direction $(\times 50,000)$

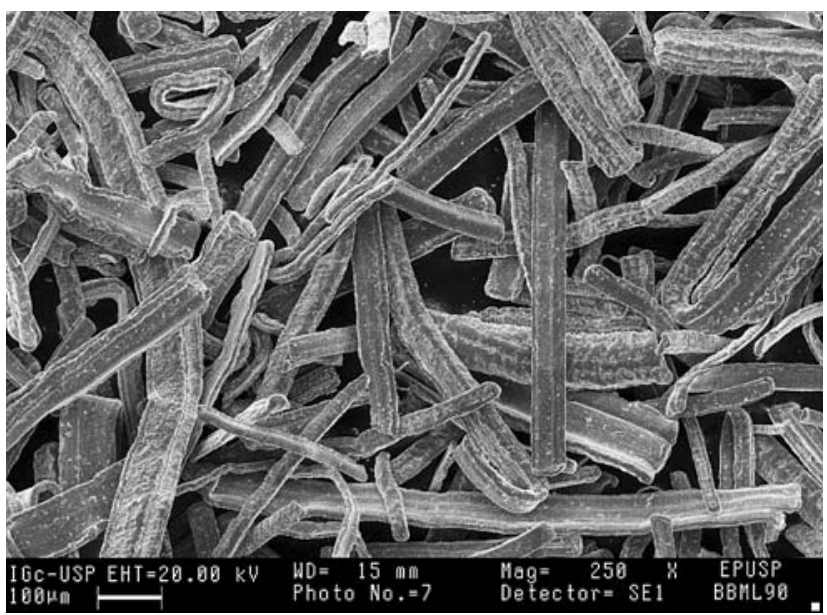

Fig. 3 Scanning electron micrograph of typical structure of powder carbon steel ML-90 $(\times 250)$

study, respectively. The purpose of the study was to evaluate the sorption capacity of PBC after surface treatments. The PBC samples received sand blasting each with power 
carbon steel. After the surface treatments, air was subsequently blown to remove free particles. Scanning electron micrographs were obtained after the activated carbon block surface treatment (Fig. 5).

The analytical protocol for pollutant analyses is specified by regulatory agencies such as EPA, American Water Works Association, American Public Health Association, Occupational Safety and Health Administration in the United States, and also in other parts of the world. This is formulated as "recipes" that describe everything the analyst needs to know to obtain a satisfactory analysis. The USEPA methods include, for example, sample collection, preservation, shipment and storage, instrumentation, apparatus, glass or plastic ware for sample containment, reagents, analytical calibration, calculations, quality control and reporting results. Table 2 lists permissible levels

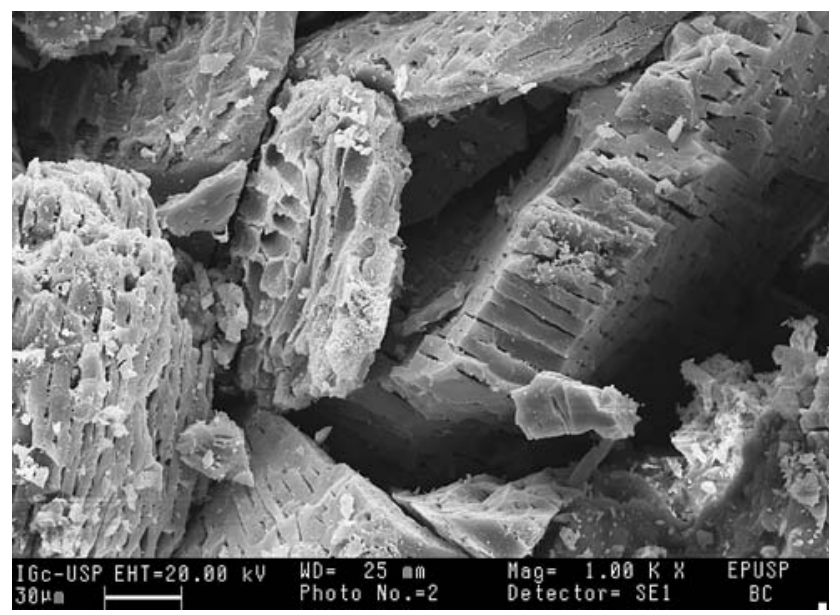

Fig. 4 Photomicrographs showing common morphology of powdered block carbon $(\times 1,000)$ with multilayer periodicity

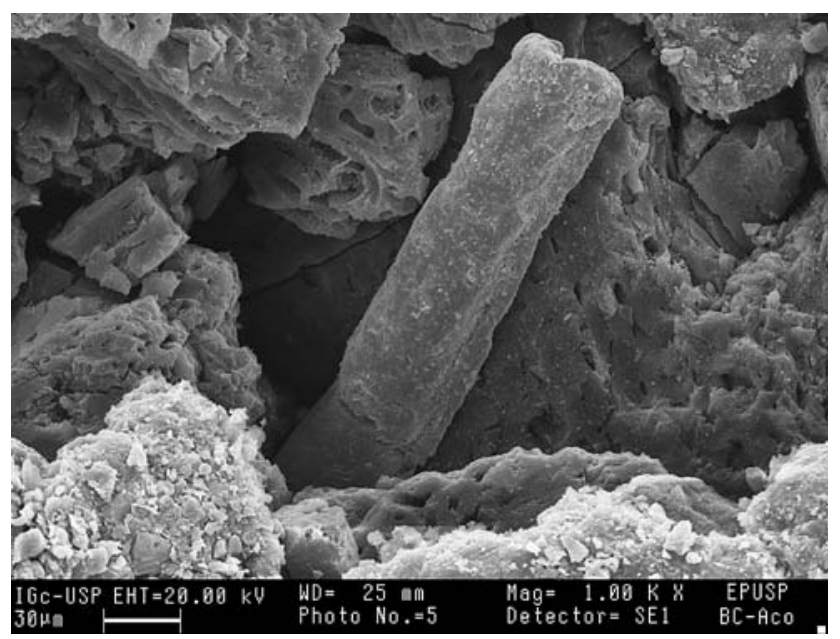

Fig. 5 SEM image of the powdered block carbon associated with a powder carbon steel $(\times 1,000)$. This electron micrograph shows carbon steel affixed to PBC used in the column tests for pollutants in drinking water according USEPA (2008) and report partial data obtained in this investigation. Considering the results for inorganic elements (minor and trace) the values exceed the limits established by Brazilian and International Legislation for potable waters.

\section{Results and discussion}

Adsorption of metals on natural zeolite

The crushed original zeolite was ground and passed through $300 \times 600 \mu \mathrm{m}$ sieves and was dried in an oven at $100 \pm 3{ }^{\circ} \mathrm{C}$ for $24 \mathrm{~h}$. Selected properties of the zeolite are presented in Table 1. The zeolite contained $67.82 \mathrm{SiO}_{2}$, $14.96 \mathrm{Al}_{2} \mathrm{O}_{3}, 0.42 \mathrm{Fe}_{2} \mathrm{O}_{3}, 0.07 \mathrm{TiO}_{2}, 1.87 \mathrm{CaO}, 0.18 \mathrm{MgO}$, $0.32 \mathrm{Na}_{2} \mathrm{O}$, and $4.47 \mathrm{~K}_{2} \mathrm{O}$, while loss on ignition was 9.37\%. The adsorption of $\mathrm{Pb}^{2+}$ and $\mathrm{Mn}^{2+}$ onto natural zeolite as a function of their concentrations was studied at $24^{\circ} \mathrm{C}$ by varying the metal concentration from 100 to $400 \mathrm{mg} \mathrm{L}^{-1}$ while keeping all other parameters constant. The results are shown in Figs. 6 and 7. Percentage adsorption for $\mathrm{Pb}^{2+}$ and $\mathrm{Mn}^{2+}$ decreases with increasing metal concentration in aqueous solutions. These results indicate that energetically less favorable sites become involved with increasing metal concentrations in the aqueous solution. According to Erdem et al. 2004 the metal uptake is attributed to different mechanisms of ionexchange process as well as to adsorption process. During the ion-exchange process, metal ions had to move through the pores of the zeolite mass, but also through channels of the lattice, and they had to replace exchangeable cations (mainly sodium and calcium). Diffusion was faster through the pores and was retarded when the ions moved through the smaller diameter channels. In this case the metal ion uptake could mainly be attributed to ion-exchange reactions in the microporous minerals of the zeolites samples. Figure 7 illustrates $K_{\mathrm{d}}$ as a function of metal ions concentrations where the $K_{\mathrm{d}}$ values increase with the decreasing concentrations of metal ions. These results indicate that energetically less favorable sites become involved with increasing metal concentration in the aqueous solution. The maximum adsorption attained was as follows: $\mathrm{Pb}^{2+} 78.7 \%$ and $\mathrm{Mn}^{2+} 19.6 \%$.

The equilibrium data for metal cations over the concentration range from 100 to $400 \mathrm{mg} \mathrm{L}^{-1}$ at $25^{\circ} \mathrm{C}$ have been correlated with the Langmuir isotherm: $C_{\mathrm{e}} / C_{\mathrm{ads}}$ $=1 / Q b+C_{\mathrm{e}} / Q$. The Langmuir model parameters and the statistical fits of the sorption data to this equation are given in Table 3. According to the $Q$ parameter, sorption on zeolite is produced following the sequence $\mathrm{Pb}^{2+}>\mathrm{Mn}^{2+}$. The metal cations are present as hexa-aqua complex ions with six surrounding water molecules in the solution and 
Table 2 Drinking water standards in the United States for inorganic chemicals and mean total content of toxic pollutants in surface water obtained in this study

\begin{tabular}{|c|c|c|c|c|}
\hline Contaminant & $\begin{array}{l}\mathrm{MCL} \text { or TT } \\
\left(\mathrm{mg} \mathrm{L}^{-1}\right)^{\mathrm{b}}\end{array}$ & $\begin{array}{l}\text { Water samples } \\
\left(\mathrm{mg} \mathrm{L}^{-1}\right)\end{array}$ & $\begin{array}{l}\text { Potential health effects from } \\
\text { ingestion of water }\end{array}$ & $\begin{array}{l}\text { Sources of contaminant in drinking } \\
\text { water }\end{array}$ \\
\hline Arsenic & 0.010 as of $01 / 23 / 06$ & 0.092 & $\begin{array}{l}\text { Skin damage or problems with } \\
\text { circulatory systems, and may } \\
\text { have increased risk of getting } \\
\text { cancer }\end{array}$ & $\begin{array}{l}\text { Erosion of natural deposits; runof } \\
\text { from orchards, runoff from glass } \\
\text { \& electronics production wastes }\end{array}$ \\
\hline Chromium (total) & 0.1 & 0.193 & Allergic dermatitis & $\begin{array}{l}\text { Discharge from steel and pulp } \\
\text { mills; erosion of natural deposits }\end{array}$ \\
\hline Lead & $\begin{array}{l}\mathrm{TT}^{\mathrm{c}} \text { action } \\
\quad \text { level }=0.015\end{array}$ & 0.172 & $\begin{array}{l}\text { Infants and children: delays in } \\
\text { physical or mental development; } \\
\text { children could show slight } \\
\text { deficits in attention span and } \\
\text { learning abilities Adults: Kidney } \\
\text { problems; high blood pressure }\end{array}$ & $\begin{array}{l}\text { Corrosion of household plumbing } \\
\text { systems; erosion of natural } \\
\text { deposits }\end{array}$ \\
\hline Manganese & $0.05^{\mathrm{d}}$ & 0.941 & $\begin{array}{l}\text { There are few reports of adverse } \\
\text { effects in humans from } \\
\text { ingesting excess manganese }\end{array}$ & $\begin{array}{l}\text { Manufacture of iron and steel } \\
\text { alloys; batteries; glass; gasoline } \\
\text { fertilizers, fungicides }\end{array}$ \\
\hline
\end{tabular}

${ }^{a}$ Maximum contaminant level (MCL) - The highest level of a contaminant that is allowed in drinking water. MCLs are set as close to MCLGs as feasible using the best available treatment technology and taking cost into consideration. MCLs are enforceable standards. Maximum contaminant level goal (MCLG) - The level of a contaminant in drinking water below which there is no known or expected risk to health. MCLGs allow for a margin of safety and are non-enforceable public health goals

b Units are in milligrams per liter $\left(\mathrm{mg} \mathrm{L}^{-1}\right)$ unless otherwise noted. Milligrams per liter are equivalent to parts per million

${ }^{c}$ Lead and copper are regulated by a Treatment Technique that requires systems to control the corrosiveness of their water. If more than $10 \%$ of tap water samples exceed the action level, water systems must take additional steps. For copper, the action level is $1.3 \mathrm{mg} \mathrm{L}^{-1}$, and for lead is $0.015 \mathrm{mg} \mathrm{L}^{-1}$

${ }^{\mathrm{d}}$ In order to enhance consumer acceptance of water resources, this advisory recommends reducing manganese concentrations to or below $0.05 \mathrm{mg} \mathrm{L}^{-1}$, the EPA's Secondary Maximum Contaminant Level for Mn. States may establish higher or lower levels depending on the local conditions

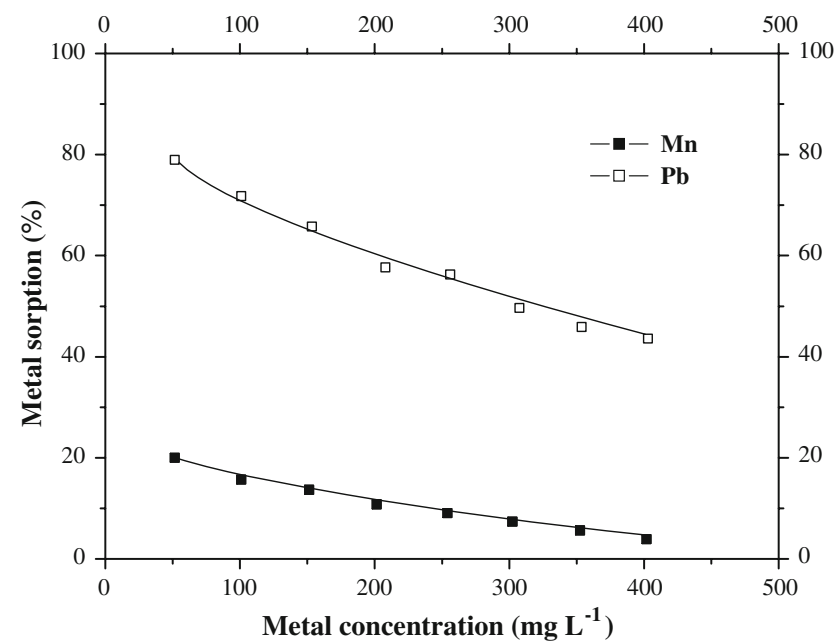

Fig. 6 Sorption of metal ions by natural zeolite sample as a function of initial concentrations: $m=10 \mathrm{~g}, V=500 \mathrm{~mL}, \mathrm{pH} 5-6$, time $6 \mathrm{~h}$

they passed the channel of zeolite in this form (Jama and Yücel 1989). Since the adsorption phenomena depend on the charge density of cations, the diameter of hydrate cations is very important. The charges of the metal cation are the same $(+2)$; therefore $\mathrm{Mn}^{2+}$ ions (the biggest diameter)

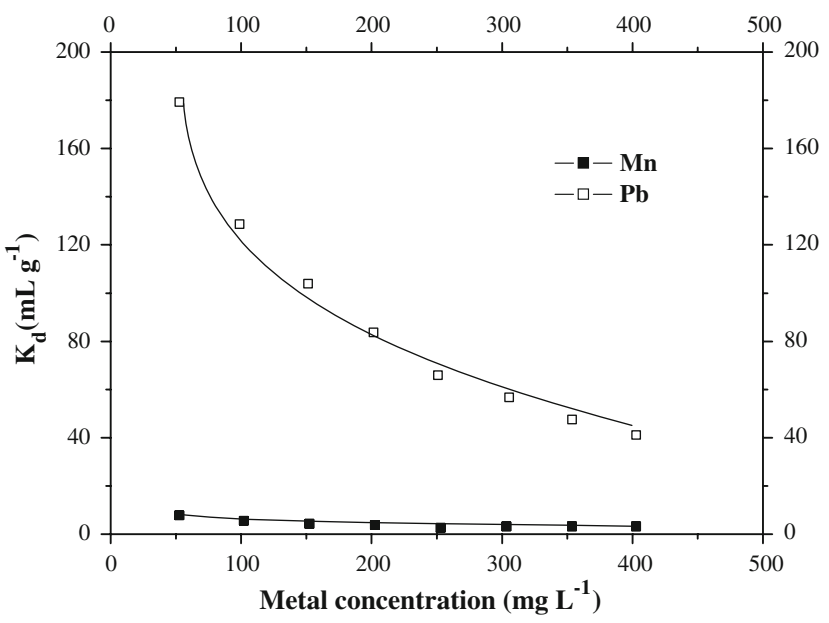

Fig. 7 Variation of metal ions on natural zeolite as a function of initial concentration: $m=10 \mathrm{~g}, V=500 \mathrm{~mL}, \mathrm{pH} 5-6$, time $6 \mathrm{~h}$

have minimum adsorption, and $\mathrm{Pb}^{2+}$ ion (the smaller diameter) has good sorption (Jama and Yücel 1989; Mier et al. 2001; Leinonen and Lehto 2001). The Langmuir model effectively described the sorption data with all $R$ values $>0.95$, according to the $b$ parameter. 
Table 3 Parameters and coefficient of the experimental data according to the Langmuir equation

\begin{tabular}{llll}
\hline Metal & $Q\left(\mathrm{mmol} \mathrm{kg}^{-1}\right)$ & $b\left(\mathrm{mmol} \mathrm{g}^{-1}\right)$ & $R^{2}$ \\
\hline $\mathrm{Pb}^{2+}$ & 168.09 & 1.25 & 0.9907 \\
$\mathrm{Mn}^{2+}$ & 78.44 & 0.34 & 0.9612 \\
\hline
\end{tabular}

Adsorption of oxyanions on synthetic goethite and modified powdered block carbon

Arsenic and chromium are two of the most toxic pollutants and causes various adverse effects on living bodies. In natural waters arsenic normally occurs in the oxidation states +3 (arsenite) and +5 (arsenate). The removal of As(III) is more difficult than the removal of $\mathrm{As}(\mathrm{V})$. Therefore, $\mathrm{As}(\mathrm{III})$ has to be oxidized to $\mathrm{As}(\mathrm{V})$ prior to its removal. Pentavalent arsenic predominates in the Carapicuíba lake. Pentavalent species predominate and are stable in oxygen rich aerobic environments. The oxidation of $\mathrm{As}(\mathrm{III})$ is possible in the presence of manganese oxide where $\mathrm{MnO}_{2}$ is reduced by $\mathrm{As}(\mathrm{III})$ to $\mathrm{Mn}^{2+}$. The present study report of $\mathrm{As}(\mathrm{V})$ and $\mathrm{Cr}(\mathrm{VI})$ by sorption onto laboratory prepared pure goethite sample and modified powdered carbon block. A combined process of powder carbon steel and powdered block carbon can effect chromium and arsenic removal on the order of 92 to $95 \%$. More than $40 \%$ of arsenate and chromate can be removed by pure goethite at $\mathrm{pH}$ values $<7$. Adsorption for oxyanions on goethite and PBC modified are seen in Fig. 8. Adsorption on each of these materials is greatest in the $\mathrm{pH}$ range of 26. The decreasing extent of adsorption with increasing $\mathrm{pH}$ is typical for the removal of anions. That $\mathrm{Cr}(\mathrm{VI})$ is less strongly adsorbed than As(V) on goethite is seen in Fig. 9. Presumably this is due to the fact that chromate forms a combination of monodentate and bidentate surface complexes with goethite and arsenate forms an inner-sphere bidentate surface complex. Based on the oxyanion-Fe distances, recent reports have concluded that three different surface complexes exist on goethite for both oxyanions: a monodentate complex, a bidentate-binuclear complex, and a bidentate-mononuclear complex (Grossl et al. 1997; Garman et al. 2004).

PBC modified appears to be the most efficient adsorbent with respect to the other seen in Fig. 8. In case of $\mathrm{As}(\mathrm{V})$, adsorption at $\mathrm{pH} 2$ could be related to the strong electrostatic attraction between positively charged surface sites for the predominant $\mathrm{As}(\mathrm{V})$ species $\mathrm{H}_{2} \mathrm{AsO}_{4}^{-}$, whereas a decrease of $\mathrm{As}(\mathrm{V})$ adsorption above $\mathrm{pH} 7$ could be due to electrostatic repulsion between the negatively charged $\mathrm{As}(\mathrm{V})$ species, $\mathrm{HAsO}_{4}^{2-}$, and the adsorbent surface, which had crossed the point of zero charge. Thus decrease in adsorption with increase in $\mathrm{pH}$ is attributed to the

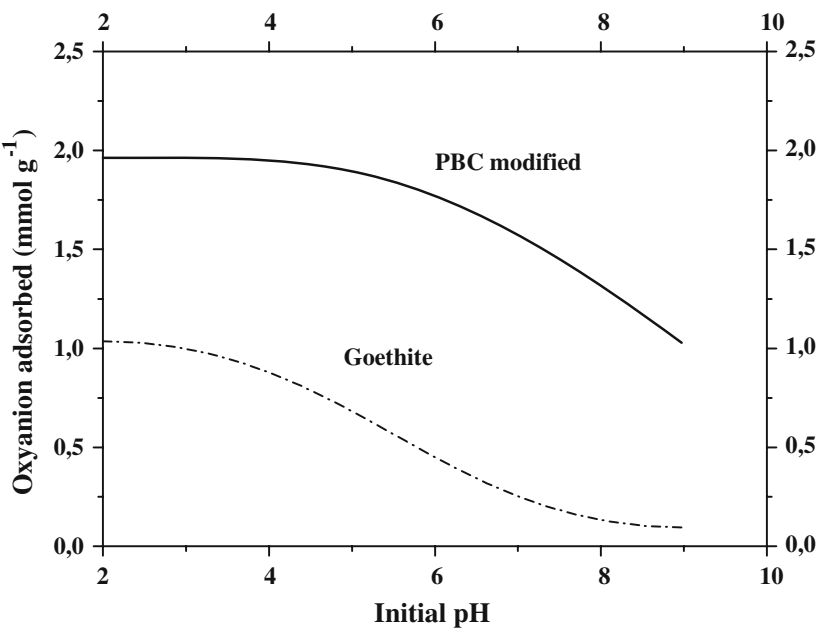

Fig. 8 Sorption fronts for oxyanions on two adsorbents

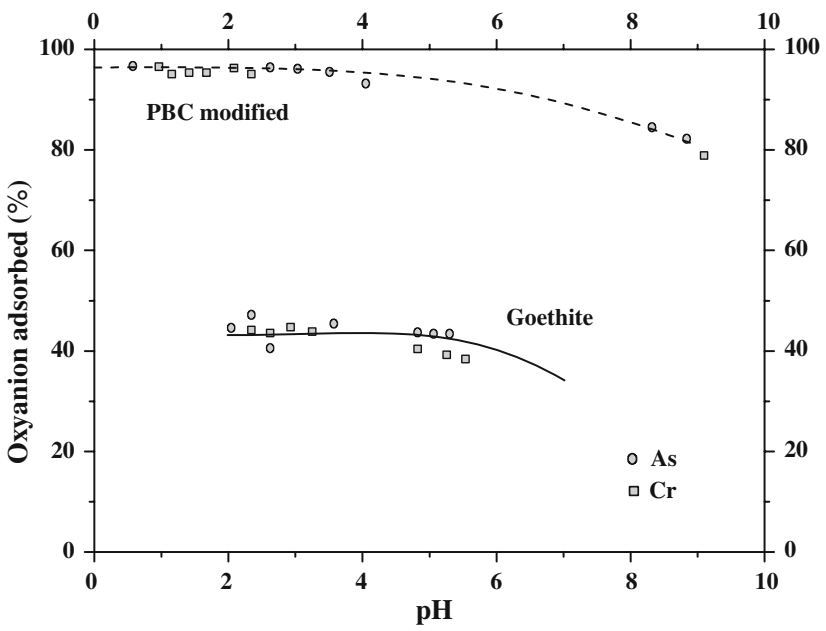

Fig. 9 Removal arsenic and chromium by PBC modified and goethite samples

adsorption of anion on a negatively charged surface. Oxyanionic arsenic species such as arsenate and arsenite adsorb at the iron oxyhydroxide surface by forming complexes with the surface sites.

In natural systems, the availability of trace element oxyanions is primarily controlled by adsorption-desorption reactions at the mineral-water interface. Numerous studies have investigated these reactions using both macroscopic and microscopic techniques. Recently, advanced spectroscopic techniques have been used to ascertain oxyanion adsorption mechanisms at the mineral-water interface. Most of these studies have focused on determining the type of surface complex formed by the oxyanion (innervs. outer-sphere complex). Inner-sphere complexes are expected to be much less bioavailable than outer-sphere complexes. However, spectroscopic evidence has shown that chromate forms inner-sphere complexes on goethite 
(Fendorf et al. 1997). It is hypothesized that arsenic will have a similar but greater effect on the adsorption of chromate on goethite. Chromate has a smaller shared charge compared with arsenite and arsenate, creating a weaker bond on adsorption. Moreover, chromate will exhibit a steeper adsorption edge compared with arsenate (i.e., reduced adsorption at near neutral $\mathrm{pH}$ values) (Grossl et al. 1997). The rate of chromate adsorption decreased with an increase in $\mathrm{pH}$ and concentration. This was attributed to a reduction in the surface potential of goethite.

According to Hamann (1990) general effectiveness of water treatment processes for arsenic and chromium removal is good in the removal range of $60-90 \%$. This particular treatment process may not be effective for the total removal of the trace elements. However, PBC modified process is employed together in a sequence in a treatment system that may achieve effective removal. The $\mathrm{pH}$ value of the solution is an important factor that controls the uptake of arsenic and chromium; the experimental results revealed that the percentage adsorption increased as the $\mathrm{pH}$ was lowered and reached $95 \%$ at $\mathrm{pH} 3$, respectively (Fig. 9). Arsenate undergoes similar sorption reactions, although is less strongly adsorbed than chromate. The sorption declined rapidly after the increase in $\mathrm{pH}$. Arsenate removal by $\mathrm{PBC}$ modified proceeded almost analogously with the chromate removal. However, experiments have been conducted to investigate the sorption of arsenic and chromium on carbon steel and removal of trace elements from drinking water with a household filtration process. The affinity of the arsenic and chromium species for $\mathrm{Fe} /$ $\mathrm{Fe}_{3} \mathrm{C}$ (iron/iron carbide) sites is the key factor controlling the removal of the elements (Campos et al. 2007).

Thermodynamically, it is impossible to eliminate corrosion of metallic material completely. Adsorption on each of these solids is greatest at $\mathrm{pH}$ values $<7$ when the adsorbent surfaces might be highly protonated and favour the uptake of hexavalent chromium in the anionic form, $\mathrm{HCrO}_{4}{ }^{-}$. The highest adsorption occurred at $\mathrm{pH} 3.0$ and was due to the reduction of $\mathrm{Cr}(\mathrm{VI})$ to $\mathrm{Cr}$ (III). Carbon steel reduces $\mathrm{Cr}(\mathrm{VI})$ to $\mathrm{Cr}(\mathrm{III})$ in equilibrium solution, and in the process, alkalinity is generated. The $\mathrm{Fe}$ (III) and $\mathrm{Cr}$ (III) formed by the redox reaction may create a mixed oxide with low solubility, thereby minimizing the chances for re-oxidation of $\mathrm{Cr}$ (III). In opposition, reduction of $\mathrm{Cr}(\mathrm{VI})$ coupled to oxidation of $\mathrm{Fe}(\mathrm{II})$ compounds may generate net acidity and chromia ions. Similar mixed $\mathrm{Cr}$ (III) and Fe(III) oxides may form. Examples of the reduction reactions for $\mathrm{Cr}(\mathrm{VI})$ that illustrate the changes associated with the use of powder carbon steel for remediation are given below:

$$
\begin{aligned}
& \mathrm{Fe}_{(\mathrm{c})}+\mathrm{CrO}_{4(\mathrm{aq})}^{2-}+0.5 \mathrm{H}_{2} \mathrm{O}_{(\mathrm{liq})}+2 \mathrm{H}_{(\mathrm{aq})}^{+} \\
& \rightarrow \mathrm{Fe}(\mathrm{OH})_{3(\mathrm{c})}+0.5 \mathrm{Cr}_{2} \mathrm{O}_{3(\mathrm{c})}
\end{aligned}
$$

$$
\begin{aligned}
& 6 \mathrm{Fe}_{(\mathrm{aq})}^{2+}+2 \mathrm{CrO}_{4(\mathrm{aq})}^{2-}+13 \mathrm{H}_{2} \mathrm{O}_{(\mathrm{liq})} \\
& \quad \rightarrow 6 \mathrm{Fe}(\mathrm{OH})_{3(\mathrm{c})}+\mathrm{Cr}_{2} \mathrm{O}_{3(\mathrm{c})}+8 \mathrm{H}_{(\mathrm{aq})}^{+}
\end{aligned}
$$

The equilibrium for hexavalent chromium and at $25^{\circ} \mathrm{C}$ in aqueous solutions are given below.

$$
\begin{aligned}
& \mathrm{HCrO}_{4(\mathrm{aq})}^{-} \rightleftharpoons \mathrm{CrO}_{4(\mathrm{aq})}^{2-}+H_{(\mathrm{aq})}^{+} \quad p K_{\mathrm{a}}=5.9 \\
& \mathrm{FeOOH}+3 \mathrm{H}_{2} \mathrm{AsO}_{4}^{-}+3 \mathrm{H}^{+}=\mathrm{Fe}\left(\mathrm{H}_{2} \mathrm{AsO}_{4}\right)_{3}+2 \mathrm{H}_{2} \mathrm{O} .
\end{aligned}
$$

\section{Conclusion}

Quality parameters from Carapicuíba lake were determined during sampling period of two years. The mean total concentrations of toxic elements in surface water decrease in the order $\mathrm{Mn}>\mathrm{Cr}>\mathrm{Pb}>$ As. A low-cost zeolites removed $\mathrm{Pb}$ from water without any pretreatment at $\mathrm{pH}$ values $<6$. According to the equilibrium studies, the selectivity sequence can be given as $\mathrm{Pb}^{2+}>\mathrm{Mn}^{2+}$. It was considered that the equilibrium is favorable for $\mathrm{Pb}^{2+}$ and unfavorable for $\mathrm{Mn}^{2+}$. It was found that the sorption phenomena depend on charge density and hydrated ion diameter. A combination of powdered block carbon and carbon steel wool removed arsenic and chromium from water. The adsorption ability of the steel wool was due to iron-anion electrochemical reactions. Arsenate is less strongly adsorbed than chromate on PBC modified. The modified powdered block carbon effectively removed $\mathrm{As}(\mathrm{V})$ and $\mathrm{Cr}(\mathrm{VI})$ while goethite removed more chromate than arsenate in the $\mathrm{pH}$ range 5-6.

Acknowledgments Financial support of the research from the Conselho Nacional de Desenvolvimento Científico e TecnológicoCNPq and Fundação de Amparo à Pesquisa do Estado de São PauloFAPESP have made this work possible. The author is grateful to Dr. Isaac Jamil Sayeg (Laboratório de Microscopia Eletrônica de Varredura-Instituto de Geociências-Universidade de São Paulo). Thanks are also extended to Paulina Faride Sayeg and Ms. Janete Cattan Sayeg for their assistance in the project.

Open Access This article is distributed under the terms of the Creative Commons Attribution Noncommercial License which permits any noncommercial use, distribution, and reproduction in any medium, provided the original author(s) and source are credited.

\section{References}

Bhattacharyya R, Chatterjee D, Jacks G (2003) Use of "red earth"low cost remedial option for arsenic removal. J Phys IV 107-117

Campos V (2002) The effect of carbon steel-wool in removal of arsenic from drinking water. Environ Geol 42(1):81-82

Campos V, Buchler PM (2005) Removal of chromate from drinking water using powder carbon steel. Environ Geol 47(7):926-930 
Campos V, Morais LC, Buchler PM (2007) Removal of chromate from aqueous solution using treated natural zeolite. Environ Geol 52(8):1521-1525

Cornell RM, Schwertmann U (2003) The iron oxides: structure, properties, reactions, occurrences and uses, 2nd edn. Wiley-VCH GmbH \& Co. KGaA, Germany, pp 703

Dragun J (1997) Chromium in soil: perspective in chemistry, health, and environmental regulation. J Soil Contamin 6(6):797 (special issue)

Driehaus W, Jekel M, Hildebrandt U (1998) Granular ferric hydroxide - a new adsorbent for the removal of arsenic from natural water. Aqua 47:30-35

Erdem E, Karapinar N, Donat R (2004) The removal of heavy metal cations by natural zeolites. J Colloid Interface Sci 280:309-314

Fendorf S, Eick MJ, Grossl P, Sparks DL (1997) Arsenate and chromate retention mechanisms on goethite. 1. Surface structure. Environ Sci Technol 31(2):315-320

Garman SM, Luxton TP, Eick MJ (2004) Kinetics of chromate adsorption on goethite in the presence of sorbed silicic acid. J Environ Qual 33:1703-1708

Grossl PR, Eick M, Sparks DL, Goldberg S, Ainsworth CC (1997) Arsenate and chromate retention mechanisms on goethite. 2. Kinetic evaluation using pressure-jump relaxation technique. Environ Sci Technol 31(2):321-326

Hamann CL (1990) Water quality and treatment, 4th edn. American Water Works Association, Denver

Jama MA, Yücel H (1989) Equilibrium studies of sodium-ammonium, potassium-ammonium, and calcium-ammonium exchanges on clinoptilolite zeolite. Sep Sci Technol 24(15):1393-1416

Leinonen H, Lehto J (2001) Purification of metal finishing waste waters with zeolites and activated carbons. Waste Manage Res 19:45-57

Mier MV, Callejas RL, Gehr R, Cisneros BEJ, Alvarez PJJ (2001) Heavy metal removal with Mexican clinoptilolite: multi-component ionic exchange. Water Res 35(2):373-380
Mohapatra M, Anand S, Das RP, Upadhyay C, Verma HC (2002) Effect of $\mathrm{Co}$ (II) doping on physical properties of synthetic goethite and their reactivity in $\mathrm{SO}_{2}-\mathrm{H}_{2} \mathrm{SO}_{4}-\mathrm{H}_{2} \mathrm{O}$ medium. Hydrometallurgy 66:125-134

Namasivayam C, Senthilkumar S (1998) Removal of arsenic(V) from aqueous solution using industrial solid waste: adsorption rates and equilibrium studies. Ind Eng Chem Res 37(12):4816-4822

Rau I, Gonzalo A, Valiente M (2000) Arsenic (V) removal from aqueous solutions by iron(III) loaded chelating resin. J Radioanal Nucl Chem 246(3):597-600

Roberts LC, Hug SJ, Ruettimann T, Billah M, Khan AW, Rahman MT (2004) Arsenic removal with iron(II) and iron(III) waters with high silicate and phosphate concentrations. Sci Technol 38:307-315

Selvaraj K, Manonmani S, Pattabhi S (2003) Removal of hexavalent chromium using distillery sludge. Bioresour Technol 89:207-211

Selvi K, Pattabhi S, Kadirvelu K (2001) Removal of Cr(VI) from aqueous solution by adsorption onto activated carbon. Biores Technol 80(1):87-89

Tokunaga S, Wasay SA, Park SW (1997) Removal of arsenic(V) ion from aqueous solutions by lanthanum compounds. Water Sci Technol 35(7):71-78

Tomašević-Čanović M (2005) Purification of natural zeolite-clinoptilolite for medical application-extraction of lead. J Serb Chem Soc 70(11):1335-1345

USEPA (2004) Drinking water health advisory for manganese. United States Environmental Protection Agency, Washington, EPA822-R-04-003

USEPA (2008) Drinking water contaminants. National primary and secundary drinking water regulations. http://www.epa.gov/ safewater/contaminants/. Accessed 10 September 2007

Wilkie JA, Hering JG (1996) Adsorption of arsenic onto hydrous ferric oxide: effects of adsorbate/adsorbent ratios and co-occurring solutes. Colloids Surf A Physicochem Eng Aspects 107:97-110 